UDC 51-77

$10.23947 / 2587-8999-2019-2-2-76-82$

\title{
The formulation and preliminary study of the model of the hype dissemination of information in society
}

\author{
A. P. Mikhailov, L. F. Yukhno** \\ Keldysh Institute of Applied Mathematics RAS, Moscow, Russia
}

The process of disseminating information in society among its possible adherents (individuals who perceive this information) under the conditions of «excitement» is considered, which means an increased level of interest in the assimilation of information. Moreover, the presence of excitement means that the influence on the rate of change of the current number of adherents, denoted $\mathrm{N}$, consists of the influence not only of the media and the influence of interpersonal contacts between individuals depending on the value of $\mathrm{N}$, but also the excitement and behavioral influence of adherents, , in addition, the rate of change of $\mathrm{N}$ over time. A corresponding mathematical model of this process is proposed and preliminary studied. The model has the form of an ordinary differential equation of the first order, not resolved with respect to the derivative. The areas of variation of the model parameters are determined for which the solution of the problem obviously exists. It is shown that under the restrictions on the parameters formulated in the work, the presence of excitement accelerates the process of society's perception of the proposed information, i.e. increases the rate of increase in the number of its followers.

Keywords: mathematical modeling, behavioral hypotheses, information dissemination, excitement, differential equations.

Introduction. Modern approaches to the study of informational interactions necessarily include the use of appropriate mathematical models based on sociological knowledge, including achievements in the field of social psychology. Moreover, taking into account the psychological characteristics of the perception of information can lead to new mathematical statements, which is the case in this paper.

When building the model, the basic model of information dissemination in society was taken as a basis [1].

From a sociological point of view, its most fundamental prerequisite is the provision that information is disseminated both through interpersonal interactions between individuals and as a result of media broadcasting. It distinguishes this approach from rumor spreading models (see, for example, [2-4]), the substantial limitation of which is that they do not take into account the influence of the media. The indicated position is confirmed empirically. Thus, in [5], which examined the influence of the media on the genocide in Rwanda during interethnic clashes in 1994, it was shown

\footnotetext{
** E-mail: yukhno@imamod.ru.
} 
that the most intense ethnic cleansing took place in villages that received the RTLM radio station that propagandizes violence, as well as in adjacent to them. From this, it was concluded that there are two mechanisms for transmitting information: through a radio station and with interpersonal communication between residents of neighboring villages.

This approach has developed in a number of areas. So, in article [6], a basic model of informational confrontation was developed, in [7] factors such as incomplete coverage of society by the media, the assimilation of information by an individual only after its repeated receipt, the possibility of forgetting information (or lost) were introduced interest in them), in [8] the confrontation was studied, in which it from the parties periodically (for a relatively short time) enhances the intensity of its broadcasting through the media. The approach was applied to modeling the confrontation between manufacturers of legal and counterfeit copies of mass innovative products using computer games as an example in [9].

Among other approaches to information interactions in society, we note the neurological model of an individual's choice of position in an informational confrontation, which focuses on the process of an individual making a decision to support a particular party on the basis of information incentives coming to him [10]. A model for distributing a political flash mob on the Internet was proposed in [11]. A number of approaches to the mathematical modeling of information processes in society focus on social networks and game-theoretic models (see, for example, $[12,13]$ ).

Formulation of the model. In the proposed model, the process of disseminating information in society will be described as a change in the number of its followers $N(t)$ in time, determined by the following three factors:

- the work of the media;

- interpersonal communications between already accomplished adherents (their current number is $N(t)$ ) and future adherents (their number is equal to $N_{0}-N(t)$ ), where $N_{0}-$ the maximum number of possible adherents of this information in society;

- rush perception of information, depending on how many adherents $N(t)$, and on the rate of change of this quantity $d N / d t$.

Let $\alpha>0, \quad \beta>0, \quad \gamma>0$ are numerical characteristics of the intensity of the influence of the described factors, respectively.

Summarizing these factors, we formulate the following problem:

$$
\frac{d N}{d t}=\left(\alpha+\beta N+\gamma \psi\left(\frac{d N}{d t}\right) N\right)\left(N_{0}-N\right), \quad N(0)=N^{0} .
$$

Here $0 \leq N(t)<N_{0}, \quad t \geq 0$, is the desired function, $\alpha, \beta, \gamma, N_{0}, N^{0}$ are the given nonnegative constants. The function $\psi(d N / d t)$ za sets the excitement factor; for its qualitative properties, see [14, p. 122] (the account of the excitement factor in modeling ethnopolitical conflicts is also shown there).

Problem (1) is the Cauchy problem for a nonlinear, unresolved relative to the derivative of an ordinary differential equation.

In order to explicitly express the derivative $d N / d t$ from equation (1), the function $\psi(z)$ approximately describe simplified formulas of the form 


$$
\begin{gathered}
\psi(z)=\frac{1}{a} z, \quad-a \leq z \leq a, \\
\psi(z)=0, \quad-a \geq z, \quad z \geq a,
\end{gathered}
$$

where $a$ is the given positive constant. Fig. 1a shows the dependence known in psychology that corresponds to the meaningful meaning of quantities (see [14]), and Fig. 1b shows its approximation (2), (3), which allows an analytical study.

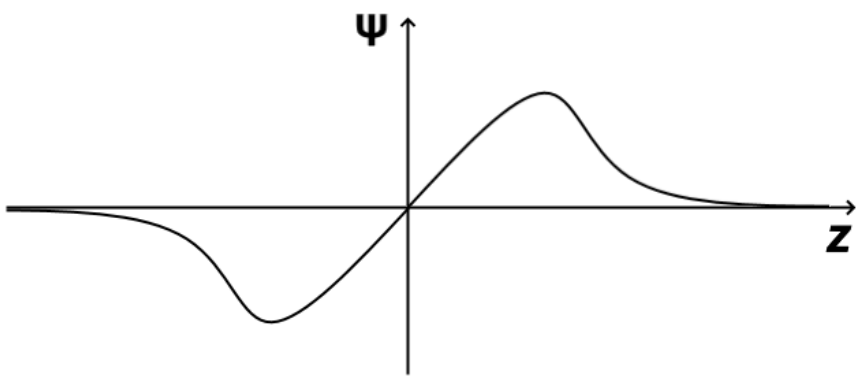

(a)

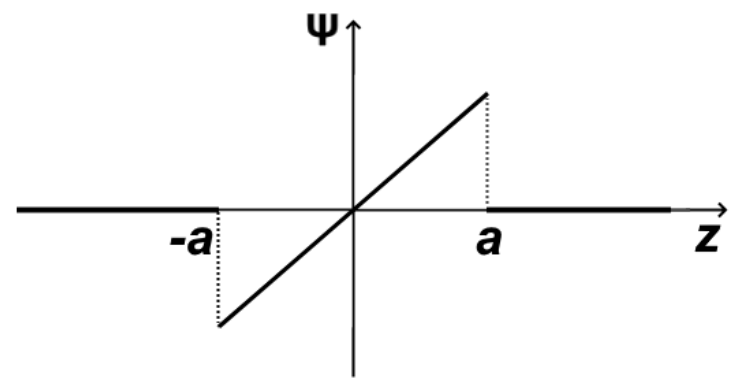

(b)

Fig. 1. A function that describes the hype factor: (a) the original form; (b) piecewise linear approximation

Study of the model. To solve problem (1)-(3), we write in explicit form the expression for the derivative $d N / d t$ from (1) taking into account (2), (3). We get the following two versions of the equation:

$$
\begin{gathered}
\frac{d N}{d t}=\frac{(\alpha+\beta N)\left(N_{0}-N\right)}{1-\frac{\gamma}{a} N\left(N_{0}-N\right)}=f_{1}(N), \quad-a \leq \frac{d N}{d t} \leq a, \\
\frac{d N}{d t}=(\alpha+\beta N)\left(N_{0}-N\right)=f_{2}(N), \quad-a \geq \frac{d N}{d t}, \quad \frac{d N}{d t} \geq a .
\end{gathered}
$$

Equation (5) with the boundary condition from (1), which describes the process of disseminating information without taking into account the hype, was considered earlier in [1], where an analytical solution of the formulated Cauchy problem was obtained and studied for it.

For a solution to equation (4) to exist, it is necessary that the right-hand side of this equation be bounded, i.e. to her denominator $1-\frac{\gamma}{a} N\left(N_{0}-N\right)$ do not vanish at any value of the input parameters. For this, obviously, the condition

$$
\frac{a}{\gamma}>\frac{N_{0}^{2}}{4}
$$

Consider the significant difficulty arising in this problem. When moving in time, for example, by successive steps $t$ in the numerical solution of the equation, it is necessary at each step to control the value of the functions $f_{1}(N)$ and $f_{2}(N)$ in order to select with certainty one of the two versions of the equation, (4) or (5). However, as is easy to see, the function $f_{1}(N)$ under condition (6) is obtained by dividing the function $f_{2}(N)$ by a positive value less than unity, and therefore, $f_{1}(N)>f_{2}(N)$ for all values $N$. This means that in this case, for example, the following situation is 
possible: when solving equation (4), the function $f_{1}(N)$ becomes larger, which requires a transition to equation (5), but at the same time $f_{2}(N)<a$, i.e. transition to equation (4) is required. Thus, the uncertainty of the choice of a variant of the equation in terms of solvability in the class of smooth functions may arise. As a result of this, in the general case, the problem is unsolvable.

However, it is possible to set such relations between the initial parameters that ensure the correct solvability of the problem. Two approaches to the formulation of such relations are proposed.

Option 1. Assume that the condition $f_{1}(N) \leq a$ for all values $0 \leq N<N_{0}$. This means that only equation (4) will be solved. (Note that this implies restriction on the domain of definition of the function $\psi(z):-a \leq z \leq a)$. We derive the dependence required for fulfilling this condition between the parameters of the problem under consideration. So, this condition implies an inequality of the form

$$
N^{2}+\left(\frac{\alpha}{\beta+\gamma}-N_{0}\right) N+\frac{a-\alpha N_{0}}{\beta+\gamma} \geq 0 .
$$

It is easy to obtain that for its implementation it is enough that the following relation takes place:

$$
a \geq \frac{\beta+\gamma}{4}\left(N_{0}+\frac{\alpha}{\beta+\gamma}\right)^{2} .
$$

Note that condition (6) imposed earlier is a consequence of condition (7). Thus, under condition (7), problem (1) is well defined and has a unique solution; in this case, only equation (4) is used.

Option 2. Consider in equation (1) function $\psi(z)$ that instead of (3) satisfies the condition,

$$
\psi(z)=\delta, \quad-a \geq z, \quad z \geq a,
$$

where $\delta$ is some given positive constant. In this case, equation (5) takes the form

$$
\frac{d N}{d t}=(\alpha+(\beta+\gamma \delta) N)\left(N_{0}-N\right)=f_{2}(N), \quad-a \geq \frac{d N}{d t}, \quad \frac{d N}{d t} \geq a
$$

Then we can establish such relations between the parameters that guarantee the fulfillment of the condition

$$
f_{1}(N)<f_{2}(N)
$$

which in turn ensures the certainty of the transition from equation (4) to equation (5) and vice versa, i.e. correct solution of the original problem. Indeed, if, when solving equation (4), the derivative $f_{1}(N)$ becomes greater than value $a$, then the derivative $f_{2}(N)$ even more than this value, which entails the transition to equation (5). Conversely, if, when solving equation (5), the derivative $f_{2}(N)$ becomes smaller than $a$, then the derivative $f_{1}(N)$ also less than $a$, what determines the transition to the equation (4).

Condition (10) implies the inequality

$$
N^{2}+\left(\frac{\alpha}{\beta+\gamma \delta}-N_{0}\right) N+\frac{a \delta-\alpha N_{0}}{\beta+\gamma \delta}>0 .
$$


Similarly to the previous one, it can be shown that its implementation is ensured by the following relation between the parameters of the problem:

$$
a>\frac{\beta+\gamma \delta}{4 \delta}\left(N_{0}+\frac{\alpha}{\beta+\gamma \delta}\right)^{2} .
$$

Condition (6) is obviously a consequence of this relation.

Comparing conditions (7) and (11), we can verify that for $\delta>1$ fulfillment (11) does not imply fulfillment (7), i.e. under condition (11) a situation is possible when $f_{2}>f_{1}>a$. This means that if condition (11) is satisfied for $\delta>1$ in the process of solving problem (1), uniquely determined transitions between equations (4) and (5) can be carried out. As a result, the function $\psi(z)$ can be considered on an unlimited interval.

When $\delta \leq 1$ condition (11) includes condition (7), i.e. for such values $\delta$ for all values $0 \leq N<N_{0}$ the condition $f_{1}(N) \leq a$ and, as follows from the above consideration of this case, only equation (4) will be solved.

Thus, for the described two options for setting the relations between the parameters, problem (1) has a solution on any change interval $t$.

Remark 1. Under the conditions for the correct solvability of the problem under consideration, for both the 1 st and 2 nd versions of the relations between the input parameters, the value of the derivative $d N / d t$ determined from equations (4), (9), i.e. taking into account the hype, more than the corresponding value $N$ determined from equation (5), i.e. for the task without taking into account the hype. It follows that the presence of excitement causes a more rapid increase in the value, i.e. «saturation» (in the sense of reaching value close to the limit value with this quantity $N_{0}$ ) occurs faster.

Remark 2. If conditions (7), (11) are not fulfilled, questions about the existence and properties of solutions to the problem require additional research.

Conclusion. In the present work, the excitement factor was introduced into the well-known model of information dissemination in society, which led to a change in the type of differential equation. This equation for the modified model in the case of a general dependence $\psi(z)$ is clearly unsolvable with respect to the derivative of the desired function (rate of change in the number of adherents). For the selected approximate version of this dependence, the equation of the model, being resolved with respect to the derivative, leads to the appearance of two equations, which makes the problem in the general case uncertain. In the present work, the relations between the initial parameters that ensure the correct solvability of the problem are distinguished. Note that a similar problem has not previously been encountered in the mathematical modeling of social processes.

The authors are deeply grateful to A.P. Petrov for useful discussions and comments. 


\section{References}

1. Samarskii A.A., Mikhailov A.P. Principles of Mathematical Modelling: Ideas, Methods, Examples. 2001. Taylor and Francis Group

2. Daley D.J., Kendall D.G. Stochastic rumors // Journal of the Institute of Mathematics and its Applications, vol. 1, pp. 42-55, 1964.

3. Maki D. P., Thompson M. Mathematical Models and Applications. Prentice-Hall, Englewood Cliffs, NJ, USA, 1973.

4. Isea R., Mayo-García R. Mathematical analysis of the spreading of a ru-mor among different subgroups of spreaders // Pure and Applied Mathematics Letters, 2015, vol. 2015, p. 50-54.

5. Yanagizawa-Drott D. Propaganda and conflict: Evidence from the Rwandan genocide // The Quarterly Journal of Economics, vol. 129, no. 4, pp. 1947-1994, 2014.

6. Mikhailov A. P., Marevtseva N. A. Models of information struggle // Math. Models Comput. Simul., Vol. 4, No. 3 (2012), P. 251-259.

7. A. P. Mikhailov, A. P. Petrov, N. A. Marevtseva, I. V. Tretiakova. Development of a Model of Information Dissemination in Society // Mathematical Models and Computer Simulations, 2014, Vol. 6, No. 5, pp. 535-541.

8. Mikhailov A. P., Petrov A. P., Proncheva O. G., Marevtseva N. A. A Model of Information Warfare in a Society Under a Periodic Destabilizing Effect // Mathematical Models and Computer Simulations, 2017, Vol. 9, No. 5, pp. 580-586.

9. Mikhailov A. P., Petrov A. P., Kalinichenko M. I., Polyakov S.V. Model-ing the Simultaneous Distribution of Legal and Counterfeit Copies of Innovative Products // Mathematical Models and Computer Simulations, 2014, Vol. 6, No. 1, pp. 25-31.

10. Petrov A. P., Maslov A. I., Tsaplin N. A. Modeling Position Selection by Individuals during Information Warfare in Society // Mathematical Models and Computer Simulations, 2016, Vol. 8, No. 4, pp. 401-408.

11. A.P. Petrov, S.A. Lebedev. Online Political Flashmob: the Case of 632305222316434 // Computational mathematics and information technologies. - 2019. - No 1. - P. 17-28.

12. Chkhartishvili A.G., Gubanov D.A., Novikov D.A. Social Networks: Models of information influence, control and confrontation. - Springer, 2019. - 158 p.

13. Chkhartishvili A., Kozitsin I. Binary Separation Index for Echo Cham-ber Effect Measuring. In 2018 Eleventh International Conference" Management of large-scale system development" MLSD, pp. 1-4. 2018. IEEE

14. Mikhailov A.P. Modelirovanie sistemy "Vlast-Obshchestvo". - M.: Fizmatlit, 2006, 144 p.

\section{Authors:}

Mikhailov Alexander P., Dr.Sci. (Math), Main Researcher at Keldysh Institute of Applied Mathematics (4, Miusskaya Sq., Moscow, Russian Federation).

Yukhno Lyudmila F., Keldysh Institute of Applied Mathematics (4, Miusskaya Sq., Moscow, Russian Federation). 
Формулировка и предварительное исследование модели ажиотажного распространения информации в социуме

\section{А. П Михайлов, Л. Ф. Юхно}

Институт прикладной математики им. М.В. Келдыша РАН, Москва, Российская Федерация

Рассматривается процесс распространения информации в социуме среди ее возможных адептов (индивидов, воспринимающих эту информацию) в условиях «ажиотажа», под которым понимается повышенный уровень интереса к усвоению информации. При этом наличие ажиотажа означает, что влияние на скорость изменения текущего количества адептов, обозначенного $N$, складывается из влияния не только средств массовой информации и зависящего от значения $N$ влияния межличностных контактов между индивидами, но и ажиотажно-поведенческого влияния адептов, зависящего, кроме того, от скорости изменения $N$ по времени. Предложена и предварительно изучена соответствующая математическая модель этого процесса. Модель имеет вид обыкновенного дифференциального уравнения первого порядка, не разрешенного относительно производной. Определены области изменения параметров модели, при которых решение поставленной задачи заведомо существует. Показано, что при сформулированных в работе ограничениях на параметры наличие ажиотажа ускоряет процесс восприятия социумом предлагаемой информации, т.е. увеличивает скорость возрастания числа ее адептов.

Ключевые слова: математическое моделирование, поведенческие гипотезы, распространение информации, ажиотаж, дифференциальные уравнения.

\section{Авторы:}

Михайлов Александр Петрович, доктор физико-математических наук, главный научный сотрудник Института прикладной математики им. М.В. Келдыша РАН (РФ, г. Москва, Миусская пл., 4).

Юхно Людмила Филипповна, Института прикладной математики им. М.В. Келдыша РАН (РФ, г. Москва, Миусская пл., 4). 